\title{
Matrix metalloproteinase 3 is a stromal marker for chicken ovarian cancer
}

\author{
JIN WON CHOI", SUZIE E. AHN*, DEIVENDRAN RENGARAJ, HEE WON SEO, \\ WHASUN LIM, GWONHWA SONG and JAE YONG HAN
}

\author{
WCU Biomodulation Major, \\ Department of Agricultural Biotechnology and Research Institute for Agriculture and Life Sciences, \\ Seoul National University, Seoul 151-921, Republic of Korea
}

Received March 14, 2011; Accepted August 12, 2011

DOI: $10.3892 / \mathrm{ol} .2011 .391$

\begin{abstract}
Matrix metalloproteinases (MMPs) are involved in the degradation of the extracellular matrix and basement membranes. Due to this, MMPs have been thought to promote invasion and metastasis of cancer cells and angiogenesis in tumors. Even though the chicken is a useful animal model for studying human ovarian cancer, no reports exist of the MMP expression pattern in chicken ovarian cancer. Therefore, we investigated the expression pattern of MMPs in chicken ovarian cancer. Results of RT-PCR and quantitative RT-PCR analyses showed MMP3 to be over-expressed in cancerous hen ovaries. In situ hybridization analysis of cancerous chicken ovaries showed that $M M P 3$ mRNA was predominantly localized in the stroma, which is similar to $M M P 3$ expression in human cancers. The results suggest that the expression pattern of $M M P 3$ mRNA in chicken ovarian cancer is similar to that in various types of human cancer. Moreover, $M M P 3$ potentially plays a significant role in developing ovarian cancer in chickens. The cell type-specific expression of $M M P 3$ makes this gene a unique marker for ovarian cancer in chickens.
\end{abstract}

\section{Introduction}

Of all the gynecologic cancers, ovarian cancer has the highest mortality rate. Even though the survival rate following early detection of the disease is relatively high, a diagnosis of ovarian cancer often occurs at a late stage in the disease. The mechanisms responsible for ovarian cancer are not completely known, and research is minimal due to a lack of suitable animal models (1).

Correspondence to: Dr Jae Yong Han, Seoul National University, 599 Gwanak-ro, Gwanak-gu, Seoul 151-921, Republic of Korea E-mail: jaehan@snu.ac.kr

${ }^{*}$ Contributed equally

Key words: chicken, ovary, ovarian cancer, matrix metalloproteinases 3 , in situ hybridization
The laying hen is a suitable animal model for human ovarian cancer due to the similarities between human and chicken ovarian cancers. Most human ovarian cancers arise spontaneously in cells derived from the ovarian surface epithelium $(2,3)$. This is consistent with chicken ovarian cancer, which originates from ovarian epithelial cells (4). Support for the hypothesis regarding incessant ovulation that explains ovarian cancer in humans $(2,3)$ is the fact that hens ovulate almost daily, resulting in genomic damage to the ovarian surface epithelium and increasing the likelihood of mutations that lead to the development of spontaneous ovarian adenocarcinoma (5). Moreover, anti-tumor antibodies common to human and chicken cancer carcinomas include cancer antigen 125, cytokeratin, pan cytokeratin, proliferating cell nuclear antigen (PCNA), carcinoembryonic antigen, cytokeratin AE1/ AE3, epidermal growth factor receptor, ERBB2, Lewis Y, selenium-binding protein 1 and tumor-associated glycoprotein 72 (6-8). Despite these similarities, further characterization of chicken ovarian cancer is crucial for a comparative study of ovarian cancers in humans and chickens.

Proteases are involved in controlling multiple biological processes and multiple diseases, including cancer (9). It was recently reported that cysteine proteases, known as cathepsins, were involved in chicken ovarian cancer (10). One of the protease groups, matrix metalloproteinases (MMPs), is involved in the degradation of the extracellular matrix and basement membranes. Due to their function, MMPs have long been considered to play an essential role in cancer progression by promoting tumor cell invasion, angiogenesis and metastasis of cancer cells (11-13). In human ovarian cancer, certain MMPs are abundantly expressed in epithelial ovarian cancer cells $(14,15)$. However, the expression of MMPs in cancerous chicken ovaries has yet to be investigated. We therefore examined the expression patterns of MMPs in cancerous and normal chicken ovaries, with a particular emphasis on MMP3.

\section{Materials and methods}

Animals. The care and experimental use of White Leghorn (WL) hens (Gallus gallus domesticus) was approved by the Institute of Laboratory Animal Resources, the Seoul National University (SNU-070823-5), Korea. The hens were maintained 
Table I. Primer sequences used for RT-PCR and cloning.

\begin{tabular}{|c|c|c|c|}
\hline Gene & $\begin{array}{l}\text { Sequence }\left(5^{\prime}-3^{\prime}\right) \text { : } \\
\text { forward and reverse }\end{array}$ & $\begin{array}{l}\text { Gene bank } \\
\text { accession no. }\end{array}$ & Product size (bp) \\
\hline$M M P 1$ & $\begin{array}{l}\text { CTAATGGGCTGCTGGCTCA } \\
\text { GACCTCTCAGGATGTTTGCG }\end{array}$ & XM_417176 & 406 \\
\hline$M M P 2$ & $\begin{array}{l}\text { GTGGCAATGGTGATGGACAG } \\
\text { TCCTGAGAAAGGCGGAAGTT }\end{array}$ & NM_204420 & 460 \\
\hline$M M P 3$ & $\begin{array}{l}\text { CACTGGGATAGGAGGGGATG } \\
\text { TCTGTGGGTGCCATTTCTGT }\end{array}$ & XM_417175.2 & 348 \\
\hline$M M P 7$ & $\begin{array}{l}\text { CCTCCTACTTTGTGCTGCCA } \\
\text { ATGATGTCTGCCTGTCCCG }\end{array}$ & NM_001006278.1 & 453 \\
\hline$M M P 9$ & $\begin{array}{l}\text { CGGCTTAGAGGTGAAGACCC } \\
\text { GGAAGGTGAAGGGGAAGACA }\end{array}$ & NM_204667.1 & 416 \\
\hline MMP11 & $\begin{array}{l}\text { CCAGCCAGACCTTGAAACAA } \\
\text { CAATCTCCTGTGGGACACCA }\end{array}$ & XM_001232776 & 491 \\
\hline MMP13 & $\begin{array}{l}\text { CGGGTGCTGTGGAAGAAATA } \\
\text { TTGGTGTAGTTGGGGCAGAC }\end{array}$ & XM_001235204 & 407 \\
\hline MMP15 & $\begin{array}{l}\text { GACGCTGGAAAACACGGAC } \\
\text { ACCACTTGCCCTTGAACACA }\end{array}$ & XM_413995 & 422 \\
\hline MMP16 & $\begin{array}{l}\text { CAACTGACCCCAGAATGTCG } \\
\text { AAAAATCCTCCСТCCCCATC }\end{array}$ & NM_205197 & 454 \\
\hline MMP17 & $\begin{array}{l}\text { TTTGGGTATCTGCCTCCTCC } \\
\text { CCTGCTGTGTGATGGTCTCC }\end{array}$ & XM_415092 & 482 \\
\hline$M M P 23 B$ & $\begin{array}{l}\text { CGTAGTGGCTTTGCTGGCTA } \\
\text { CAAGTTCCCCTGTTGTTCCA }\end{array}$ & XM_417569 & 425 \\
\hline MMP24 & $\begin{array}{l}\text { CGACTCTTCCTGTTCGCAGA } \\
\text { TCGCTCTCTTGTCCTCGTTG }\end{array}$ & XM_417326 & 498 \\
\hline MMP27 & $\begin{array}{l}\text { CAGGAAAACCAGACACCGAG } \\
\text { GAGCAGCAACCAGGAACAAA }\end{array}$ & NM_205000 & 423 \\
\hline MMP28 & $\begin{array}{l}\text { CAGCACCTACTACTGCCACTCC } \\
\text { AATAGCGGTCATCCCGAAAG }\end{array}$ & XM_415771 & 500 \\
\hline GAPDH & $\begin{array}{l}\text { CACAGCCACACAGAAGACGG } \\
\text { CCATCAAGTCCACAACACGG }\end{array}$ & NM_204305 & 443 \\
\hline
\end{tabular}

in a standard management program at the University Animal Farm at Seoul National University. The procedures used for animal management, reproduction and embryo manipulation followed the standard operating protocols of our laboratory.

Tissue samples. Cancerous $(\mathrm{n}=5)$ ovaries were obtained from 2- and 3-year-old WL hens with spontaneously developed ovarian cancer. Normal $(n=3)$ ovaries were obtained from 2- and 3-year-old healthy WL hens without any histological changes in the ovaries. Sections of these ovaries were frozen or embedded in paraffin for further analysis. For diagnosis, paraffin-embedded tissues were sectioned at $5 \mu \mathrm{m}$ and stained with hematoxylin and eosin.

RT-PCR analysis. Total RNA was extracted from frozen tissues by TRIzol reagent (Invitrogen, Carlsbad, CA, USA), and cDNA was synthesized using AccuPower ${ }^{\circledR}$ RT PreMix
(Bioneer, Daejeon, Korea). Specific primer sets were used for RT-PCR (Table I). PCR amplification was performed as follows: $95^{\circ} \mathrm{C}$ for $3 \mathrm{~min}$; followed by 30 cycles of $95^{\circ} \mathrm{C}$ for $20 \mathrm{sec}, 60^{\circ} \mathrm{C}$ for $40 \mathrm{sec}$ and $72^{\circ} \mathrm{C}$ for $1 \mathrm{~min}$; and a final extension of $72^{\circ} \mathrm{C}$ for $5 \mathrm{~min}$. PCR products were analyzed on a $1 \%$ agarose gel stained with ethidium bromide.

Quantitative RT-PCR analysis. Quantitative RT-PCR was performed using SYBR-Green (Sigma, St. Louis, MO, USA) and a StepOnePlus real-time PCR system (Applied Biosystems, Foster City, CA, USA). Relative quantification of gene expression was calculated using the formula $2^{-\Delta \Delta \mathrm{Ct}}$, where $\Delta \Delta \mathrm{Ct}=$ $\left(\mathrm{Ct}_{\text {target gene }}-\mathrm{Ct}_{\text {GAPDH }}\right)_{\text {cancerous tissue }}-\left(\mathrm{Ct}_{\text {target gene }}-\mathrm{Ct}_{\text {GAPDH }}\right)_{\text {normal tissue. }}$ The information for the primer sets is shown in Table II.

In situ hybridization. In situ hybridization was conducted as previously described (16). For hybridization probes, PCR 
Table II. Primer sequences used for quantitative RT-PCR.

\begin{tabular}{llcc}
\hline Gene & \multicolumn{1}{c}{$\begin{array}{c}\text { Sequence }\left(5^{\prime}-3^{\prime}\right): \\
\text { forward and reverse }\end{array}$} & $\begin{array}{c}\text { Gene bank } \\
\text { accession no. }\end{array}$ & Product size (bp) \\
\hline$M M P 3$ & $\begin{array}{l}\text { ACCTGGGCTTTCCCAGAAGT } \\
\text { CTGAAGGGCAGCATCAACGA }\end{array}$ & XM_417175.2 & 194 \\
GAPDH & $\begin{array}{l}\text { ACACAGAAGACGGTGGATGG } \\
\text { GGCAGGTCAGGTCAACAACA }\end{array}$ & NM_204305 & 193 \\
\hline
\end{tabular}

products were generated from ovarian cancer cDNA with the primers used in RT-PCR analysis. Products were then gel-extracted and cloned into pGEM-T Easy Vector (Promega, Madison, WI, USA). Following the verification of sequences, a DIG-labeled RNA probe was prepared using a DIG RNA labeling kit (Roche Applied Science, Indianapolis, IN, USA). Frozen sections $(10 \mu \mathrm{m})$ were mounted on slides pretreated with 3-aminopropyltriethoxysilane (Sigma), dried on a $50^{\circ} \mathrm{C}$ slide warmer, fixed in $4 \%$ paraformaldehyde in phosphate-buffered saline (PBS), treated with $1 \%$ Triton X-100 in PBS for $20 \mathrm{~min}$, washed three times in PBS and incubated with a prehybridization mixture [50\% formamide and $5 \mathrm{X}$ standard saline citrate (SSC)] for $15 \mathrm{~min}$ at room temperature. Following prehybridization, sections were incubated in a hybridization mixture (50\% formamide, $5 \mathrm{X} \mathrm{SSC}, 10 \%$ dextran sulfate sodium salt, $0.02 \%$ bovine serum albumin, $250 \mu \mathrm{g} / \mathrm{ml}$ yeast tRNA and denatured DIG-labeled cRNA probes) for $18 \mathrm{~h}$ at $55^{\circ} \mathrm{C}$ in a humidified chamber. Sections were then washed for stringency in a series of solutions containing formamide and SSC. Following blocking with $1 \%$ blocking reagent (Roche), sections were incubated overnight with sheep anti-DIG antibody conjugated to alkaline phosphatase (Roche). Following incubation, a visualization solution (0.4 mM 5-bromo-4-chloro-3-indolyl phosphate, $0.4 \mathrm{mM}$ nitroblue tetrazolium, and $2 \mathrm{mM}$ levamisole; Sigma) was used. Sections were counterstained with $1 \%(w / v)$ methyl green (Sigma). Images were captured with a Zeiss Axiophot light microscope equipped with an AxioCam HRc camera (Carl Zeiss, Inc., NY, USA).

Statistical analysis. Statistical analysis was performed using the Student's t-test using the SAS program (SAS Institute, Cary, NC, USA). $\mathrm{P}<0.05$ was considered to be statistically significant.

\section{Results}

Pathological characteristics of chicken ovarian cancer. Normal ovaries had typically developing follicles surrounded by stroma (Fig. 1A). The morphology of cancerous ovaries was entirely different, showing gland-like growth of cancer cells invading stromal tissues (Fig. 1B). The difference between normal and cancerous ovaries was similar to that reported previously $(17,18)$.

Increased expression of MMP3 in cancerous ovaries. We initially performed RT-PCR analysis to determine the expression of MMPs that have been identified in chickens. MMP3
mRNA was markedly expressed in cancerous ovaries but almost undetectable in normal ovaries (Fig. 2A), whereas the expression of the remaining MMPs were weak or undetectable in cancerous and normal ovaries (data not shown). Therefore, further study was focused on MMP3.

To measure relative mRNA levels between normal and cancerous ovaries, we performed quantitative RT-PCR. As expected, MMP3 mRNA expression in cancerous ovaries was approximately 16 -fold higher than that in normal ovaries $(\mathrm{P}<0.05$, Fig. 2B).

Localization of MMP3 mRNA in normal and cancerous ovaries. The expression pattern for $M M P 3$ was further analyzed by the localization of MMP3 mRNA by in situ hybridization. The results indicated an absence of the cellspecific expression of MMP3 mRNA in normal ovaries (Fig. 3A and D), whereas abundant MMP3 mRNA was observed in the stroma between the gland-like areas in the cancerous ovaries (Fig. 3B, C, E and F).

\section{Discussion}

MMP3 (also known as stromelysin-1) plays significant roles in regulating extracellular matrix remodeling and in activating other MMPs (19). Over-expression of MMP3 has also been demonstrated in various types of cancer (20). In human cancer, MMPs are also commonly expressed in the stromal cells rather than in the tumor cells: expression of MMPs in stromal cells has been reported in breast, colorectal, lung, prostate, and pancreatic cancers (20). Our results also show that $M M P 3$ mRNA is localized in stromal cells in chicken ovarian cancer suggesting that the roles of MMP3 in cancer are conserved between chickens and humans, and the expression of $M M P 3$ may be regulated by similar mechanisms in the two species. In humans, cancer cells induce $M M P 1,2$ and 3 expression by secreting signaling molecules known as extracellular matrix metalloproteinase inducers $(21,22)$. However, further studies are necessary to determine the detailed mechanism(s) of tumorigenesis in chicken ovaries.

Although the role of MMP3 in cancer has not been fully elucidated, certain studies have revealed its tumorigenic functions. Sternlicht et al showed that MMP3 over-expression in transgenic mice leads to enhanced mammary carcinogenesis (23), and Witty et al showed that MMP3 targets relevant substrates to promote apoptosis in neighboring epithelial cells, which is relevant for cancer (24). In addition to their ability to degrade major protein components of the extracellular matrix or the basement membrane, MMPs play a role in 

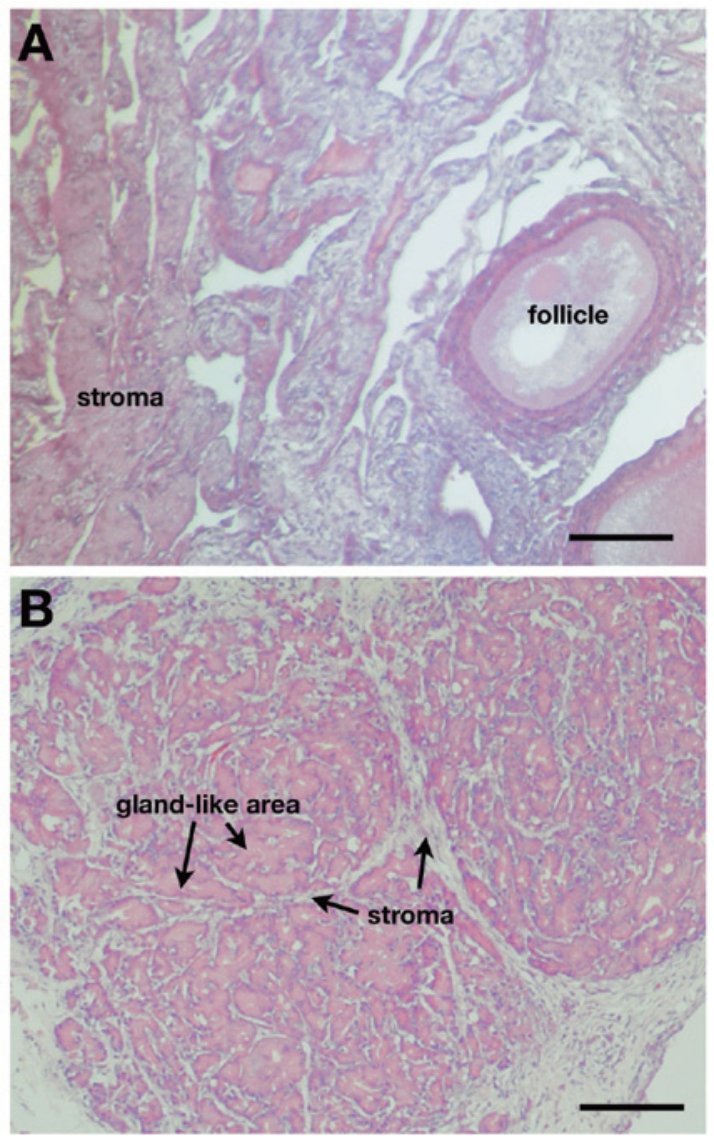

Figure 1. Hematoxylin and eosin staining of (A) normal and (B) cancerous hen ovary. Scale bar, $100 \mu \mathrm{m}$.
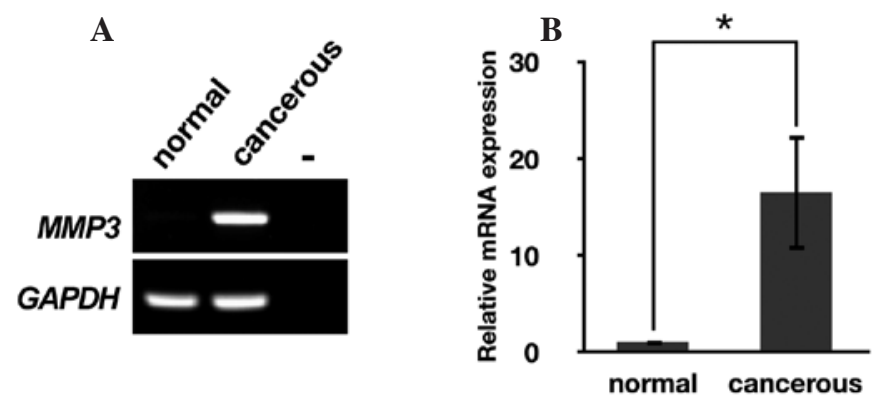

Figure 2. Increased expression of $M M P 3$ mRNA in normal and cancerous chicken ovaries. (A) RT-PCR analysis of ovaries. (B) Relative mRNA expression of $M M P 3$ between normal and cancerous ovaries from chickens indicated that $M M P 3 \mathrm{mRNA}$ was greater in cancerous ovaries (mean $\pm \mathrm{SEM}$, $\mathrm{P}<0.05)$.

the early stages of tumorigenesis by stimulating cell proliferation and modulation of angiogenesis (25). A focus on the early stages of ovarian cancer in chickens may reveal new roles for MMPs in the early developmental stages of cancer and thus improve the ability of medical professionals to make an early diagnosis.

In conclusion, this study has demonstrated the overexpression of $M M P 3$ in chicken ovarian cancer. The expression pattern of $M M P 3$ is relatively similar to that of MMPs in human cancer. The cell type-specific expression of the $M M P 3$ gene renders this gene a unique marker for epithelial chicken ovarian cancer and suggests the crucial role MMP3 plays in its development.

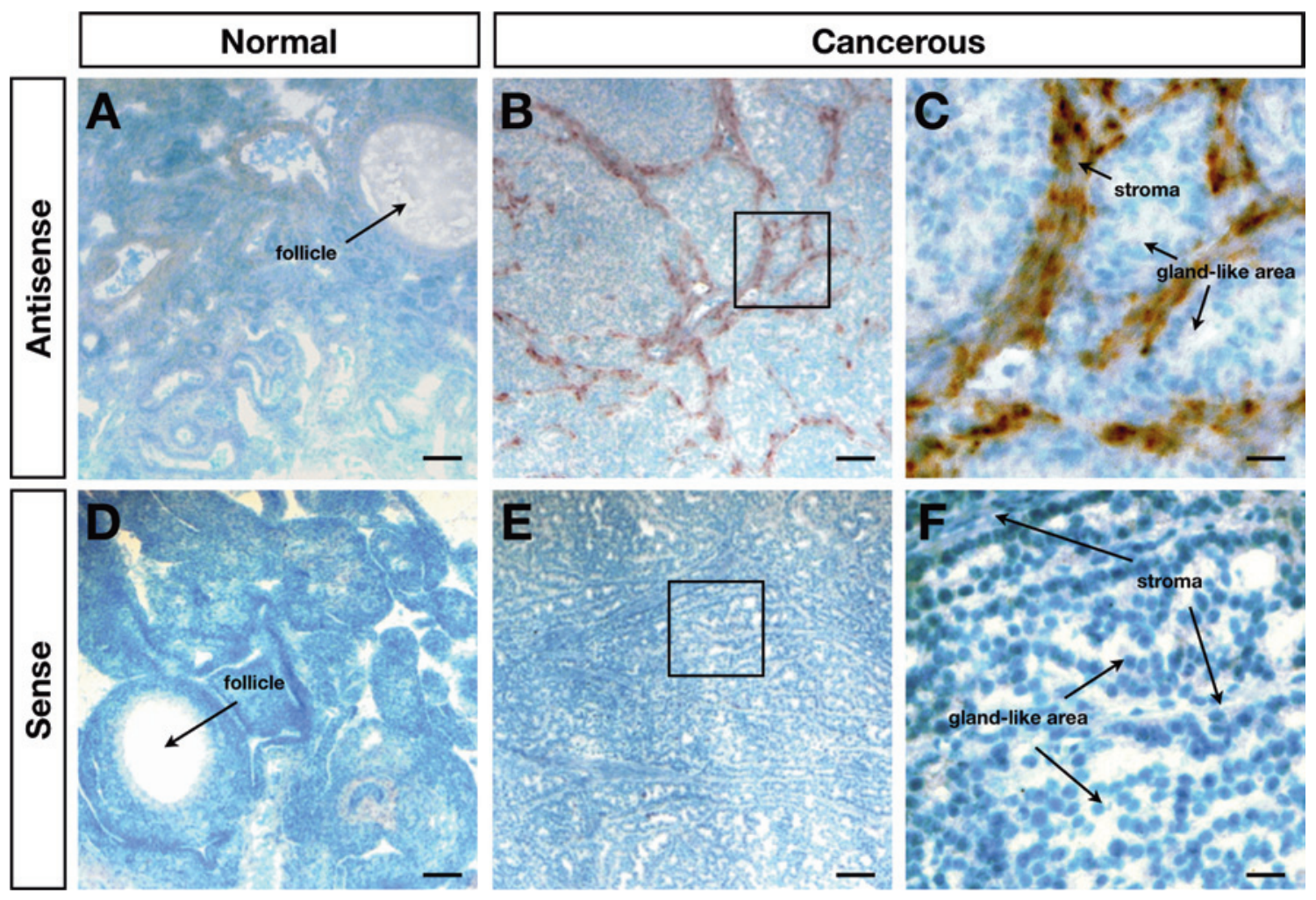

Figure 3. In situ hybridization analysis of $M M P 3$ mRNA in normal and cancerous chicken ovaries. (A) No cell-specific localization of $M M P 3$ mRNA was observed in normal ovaries. (B and C) $M M P 3$ mRNA was markedly expressed in the stroma of cancerous ovaries. (D-F) Negative controls with the sense probe. Scale bar, $100 \mu \mathrm{m}$ (A, B, D and E) and $25 \mu \mathrm{m}$ (C and F). 


\section{Acknowledgements}

This study was supported by the Mid-career Researcher Program through an NRF grant funded by the MEST (No. 2009-0083687) and the World Class University program (R31-10056) through the National Research Foundation of Korea funded by the Science and Technology Ministry of Education. The authors would like to express their appreciation to Dr Fuller W. Bazer (Texas A\&M University, USA; and Seoul National University, Korea) for assistance with manuscript preparation and helpful discussions.

\section{References}

1. Orsulic S: Ovarian cancer. In: Mouse Models of Human Cancer. Holland EC (ed). Whiley-Liss, Inc., New Jersey, pp171-187, 2004.

2. Auersperg N, Edelson MI, Mok SC, Johnson SW and Hamilton TC: The biology of ovarian cancer. Semin Oncol 25 281-304, 1998.

3. Fathalla MF: Incessant ovulation-a factor in ovarian neoplasia? Lancet 2: 163, 1971.

4. Fredrickson TN: Ovarian-tumors of the hen. Environ Health Perspect 73: 35-51, 1987.

5. Murdoch WJ, Van Kirk EA and Alexander BM: DNA damages in ovarian surface epithelial cells of ovulatory hens. Exp Biol Med 230: 429-433, 2005

6. Zhuge Y, Lagman JA, Ansenberger K, et al: CYP1B1 expression in ovarian cancer in the laying hen Gallus domesticus. Gynecol Oncol 112: 171-178, 2009.

7. Stammer K, Edassery SL, Barua A, et al: Selenium-binding protein 1 expression in ovaries and ovarian tumors in the laying hen, a spontaneous model of human ovarian cancer. Gynecol Oncol 109: 115-121, 2008.

8. Rodriguez-Burford C, Barnes MN, Berry W, Partridge EE and Grizzle WE: Immunohistochemical expression of molecular markers in an avian model: a potential model for preclinical evaluation of agents for ovarian cancer chemoprevention. Gynecol Oncol 81: 373-379, 2001.

9. Lopez-Otin C and Bond JS: Proteases: Multifunctional enzymes in life and disease. J Biol Chem 283: 30433-30437, 2008.

10. Ahn SE, Choi JW, Rengaraj D, et al: Increased expression of cysteine cathepsins in ovarian tissue from chickens with ovarian cancer. Reprod Biology and Endocrinol 8: 100, 2010.

11. Wolf K, Wu YI, Liu Y, et al: Multi-step pericellular proteolysis controls the transition from individual to collective cancer cell invasion. Nat Cell Biol 9: 893-904, 2007.
12. Bartolome RA, Ferreiro S, Miquilena-Colina ME, et al: The chemokine receptor CXCR4 and the metalloproteinase MT1-MMP are mutually required during melanoma metastasis to lungs. Am J Pathol 174: 602-612, 2009.

13. Bergers G, Brekken R, McMahon G, et al: Matrix metalloproteinase-9 triggers the angiogenic switch during carcinogenesis. Nat Cell Biol 2: 737-744, 2000

14. Stadlmann S, Pollheimer J, Moser PL, et al: Cytokine-regulated expression of collagenase-2 (MMP-8) is involved in the progression of ovarian cancer. Eur J Cancer 39: 2499-2505, 2003.

15. Kenny HA and Lengyel E: MMP-2 functions as an early response protein in ovarian cancer metastasis. Cell Cycle 8: 683-688, 2009.

16. Rengaraj D, Kim DK, Zheng YH, Lee SI, Kim H and Han JY: Testis-specific novel transcripts in chicken: in situ localization and expression pattern profiling during sexual development. Biol Reprod 79: 413-420, 2008.

17. Giles JR, Shivaprasad HL and Johnson PA: Ovarian tumor expression of an oviductal protein in the hen: a model for human serous ovarian adenocarcinoma. Gynecol Oncol 95: 530-533, 2004.

18. Hales DB, Zhuge Y, Lagman JAJ, et al: Cyclooxygenases expression and distribution in the normal ovary and their role in ovarian cancer in the domestic hen (Gallus domesticus). Endocrine 33: 235-244, 2008.

19. Kucukali CI, Aydin M, Ozkok E, et al: Do schizophrenia and bipolar disorders share a common disease susceptibility variant at the MMP3 gene? Prog Neuro-Psychopharmacol Biol Psychiatry 33: 557-561, 2009.

20. Nelson AR, Fingleton B, Rothenberg ML and Matrisian LM: Matrix metalloproteinases: biologic activity and clinical implications. J Clin Oncol 18: 1135-1149, 2000.

21. Kataoka H, DeCastro R, Zucker S and Biswas C: Tumor cell-derived collagenase-stimulatory factor increases expression of interstitial collagenase, stromelysin, and $72-\mathrm{kDa}$ gelatinase. Cancer Res 53: 3154-3158, 1993.

22. Biswas C, Zhang Y, Decastro R, et al: Human tumor cell-derived collagenase stimulatory factor (renamed Emmprin) is a member of the immunoglobulin superfamily. Cancer Res 55: 434-439, 1995.

23. Sternlicht MD, Lochter A, Sympson CJ, et al: The stromal proteinase MMP3/stromelysin-1 promotes mammary carcinogenesis. Cell 98: 137-146, 1999.

24. Witty JP, Lempka T, Coffey RJ and Matrisian LM: Decreased tumor-formation in 7,12-dimethylbenzanthracene-treated stromelysin-1 transgenic mice is associated with alterations in mammary epithelial-cell apoptosis. Cancer Res 55: 1401-1406, 1995.

25. Egeblad M and Werb Z: New functions for the matrix metallo proteinases in cancer progression. Nat Rev Cancer 2: 161-174, 2002. 